\title{
MEMBANGUN RELASI AGAMA DAN ILMU PENGETAHUAN
}

\author{
Zaprulkhan \\ STAIN Bangka Belitung \\ zaprulkhan@g.mail.com
}

\begin{abstract}
Abstrak
Kehidupan dunia modern yang positvistik telah menempatkan ilmu pengetahuan atau sains pada posisi yang terpisah dari agama. Sehingga ilmu pengetahuan seringkali lepas sama sekali dari nilai-nilai etis religius. Artikel ini fokus pada upaya membangun relasi agama dengan ilmu pengetahuan. Kajian ini diawali dengan menyoroti bagaimana prinsipprinsip dalam penyelidikan ilmiah dan agama, kemungkinan pertemuan keduanya, serta diakhiri dengan catatan kritis terhadap kekurangan masing-masing. Kendati sains mempunyai metodenya sendiri yang bersifat ilmiah, sebagaimana agama juga memiliki metodenya tersendiri untuk menyibak makna, namun keduanya tidak seharusnya saling menegasikan eksistensi masing-masing. Meskipun sains dan agama mempunyai wilayah yurisdiksinya masing-masing, namun keduanya dapat saling berbagi. Sains dan agama bisa menjadi mitra dalam menafsirkan alam semesta dengan pelbagai metodenya yang saling melengkapi. Dalam hubungan dialogis antara keduanya, agama bisa mendukung segala kegiatan ilmiah, sebaliknya sains bisa memperbaiki pemahaman religius demi kesejahteraan umat manusia. Sebagaimana dinyatakan Albert Einstein: ilmu pengetahuan tanpa agama lumpuh, agama tanpa ilmu pengetahuan buta..
\end{abstract}

\section{Abstract}

TO BUILD RELATIONS BETWEEN RELIGION AND SCIENCE. The positvistic life of the modern world has put science in a position separate from religion. Therefore, science is often completely free from any religious, ethical values. This article focuses on an attempts to build relationships between religion and science. This study begins by highlighting the principles in scientific inquiry and religion, the possibility of reconciling them, and concludes with 
a critical note of the weakness of each. Although science has its own method of a scientific nature, similarly, religion has also its own method to uncover the meaning, but they should not negate the existence of each. Despite the fact that science and religion have jurisdiction respectively, both can share. Science and religion can be a partner in the interpretation of the universe with various complementary methods. In a dialogic relationship between the two, religion can support all scientific activities, whereas science can improve religious understanding for the welfare of mankind. As Albert Einstein stated: science without religion is lame, religion without science is blind..

Kata Kunci : Integrasi, Sains, Agama

\section{A. Pendahuluan}

Keimanan Einstein kepada Tuhan mendasari pemikiran ilmiahnya, dan pada Saat yang sama pandangan agamanya sangat dipengaruhi oleh pemikiran ilmiahnya. Ketakjubannya pada penemuan sains membawa Einstein kepada Tuhan. Jika pandanagan agamanya mempengaruhi pemikiran ilmiahnya, pada gilirannya pemikiran ilmiahnya mewarnai pandangan agamanya. Einstein mewakili model integrasi salah satu bentuk interaksi antara agama dan ilmu pengetahuan. ${ }^{1}$ Dalam integrasi, agama menyumbangkan ajarannya pada ilmu pengetahuan dan ilmu pengetahuan menghadiahkan penemuannya pada agama.

Dengan meminjam metafora Einstein, dapat dikatakan bahwa agama memberikan tongkat kepada sains, agar ia tidak berkutat hanya pada pengamatan empiris: agar ia menjelajah dunia yang lebih luas. Sains memberikan lampu agar agama melihat cahaya dalam kegelapan; agar tidak tenggelam dalam takhayul dan kepercayaan palsu. Salah satu contoh agama tanpa

${ }^{1}$ Dalam perbincangan mengcnai hubungan antara agama dan ilmu pengetahuan, setidaknya menurut Barbour terpola empat model: konflik, independensi, dialog, dan integrasi. Lihat dua bukunya Ian G. Barbour, Juru Bicara Tuhan, terj. E.R. Muhammad, (Bandung: Mizan, 2002). Lihat juga Ian G. Barbour, Menemukan Tuhan dalam Sains Kontemporer dan Agama, terj. Fransiskus Borgias, (Bandung: Mizan, 2005). Sedangkan menurut Haught juga ada empat walau dengan variasi yang sedikit berbeda: konflik, kontras, kontak, dan konfirmasi. Lihat John F. Haught, Perjumpaan Sains dan Agama, terj. Fransiskus Borgias, (Bandung: Mizan, 2004). 
ilmu adalah kultus atau gerakan-gerakan sempalan (cults).

Pada 1978, 914 pengikut Jini Jones melakukan bunuh diri massal di Guyana Utara, di sebuah desa yang mereka sebut Jamestown. ${ }^{2}$ April 1996, Asahara -guru besar dan pemimpin ruhaniah Aum Shinrikyo- diseret ke pengadilan karena didakwa membunuh 25 orang, termasuk 11 orang korban gas saraf sarin, yang disebarkan para pengikutnya di kereta bawah tanah Tokyo. Dan pada Maret 1997 terjadi bunuh diri massal di wilayah San Diego, California karena terjebak oleh pseudo-agama. ${ }^{3}$ Mereka beragama tanpa ilmu. ${ }^{4}$

Dalam konteks ini. sains dan agama tampaknya harus saling berdialog dan berinteraksi sehingga akhirnya bisa berintegrasi. Agaknya inilah paradigma yang diusung oleh Holmes Rolston 111 dalam kajiannya terhadap sains dan agama. ${ }^{5}$ Dalam tilikan Rolston, kendati sains dan agama mempunyai wilayah yurisdiksinya masing-masing namun keduanya dapat saling berbagi. Sains dan agama bisa menjadi mitra dalam menafsirkan alam semesta dengan pelbagai metodenya yang saling melengkapi. Karena itu, tulisan ini terlebih dulu akan menyoroti bagaimana prinsip-prinsip dalam penyelidikan ilmiah dan agama, kemungkinan pertemuan keduanya, serta diakhiri dengan catatan kritis terhadap kekurangan masing-masing sehingga dapat saling mengisi dan berintegrasi.

\section{B. Prinsip-Prinsip Dalam Penyelidikan Ilmiah}

Sejak Renaisance, gagasan dunia yang mekanis dan matematis telah dikemukakan oleh para ilmuwan. Ilmu pengetahuan atau sains memiliki posisi otonom, lepas dari pengaruh Filsafat dan agama. Dari sini, ilmu pengetahuan didirikan atas dasar beberapa pengandaian yang dirumuskan sebagai prinsip atau metode. Pertama, logika ilmiah menyatakan bahwa proposisi hanya berarti bila dapat diverifikasi dengan pengalaman indrawi.

${ }^{2}$ Nurcholish Madjid, Islam Doklrin dan Peradaban, (Jakarta: Paramadina, 1995), h. 353-4.

${ }^{3}$ Komaruddin Hidayat, Tragedi Raja Midas, (Jakarta: Paramadina, 1998), h. 131.

${ }^{4}$ Rakhmat, Psikologi..., h. 52-59.

${ }^{5}$ Holmes Rolston III, Science and Religion A Critical Survey, (New York: Random House, 1987), h. 4. 
Seorang ilmuwan dapat menentukan apakah sebuah proposisi benar atau salah dengan menghubungkan proposisi tersebut dengan pembuktian empiris. Jika sebuah proposisi tidak bisa dibuktikan secara empiris, maka proposisi itu tidak berarti, not make sense, atau nonsense. ${ }^{6}$

Kedua, pengetahuan ilmiah harus bersifatobjektif.Iniberarti bahwa seorang ilmuwan sama sekali tidak boleh dipengaruhi oleh faktor subyektifitasnya seperti, perasaan, kepercayaan, nilai-nilai, moral/etis, dalam melakukan penelitian. Di sini asumsi bebas nilai menyatakan bahwa karena peneliti terpisah, maka setiap penelitian ilmiah selalu bebas nilai. Nilai bersifat subjektif, sedangkan dunia pengamatan bersifat objektif. ${ }^{7}$

Ketiga, sains tidak berurusan dengan fenomena yang unik (idiografis), karena gejala yang unik tidak memungkinkan untuk memastikan hal yang akan terjadi (prediksi) dan kontrol. Padahal prediksi dan kontrol merupakan tujuan sains yang terpenting. Seluruh teknologi modern, di bidang kedokteran, pertanian, meteorologi, komunikasi, transportasi dan lainnya didasarkan atas pengetahuan tentang reaksi-reaksi yang berulang kali terjadi, sehingga dapat ditentukan, dikendalikan, atau dimanipulasi. ${ }^{8}$

Keempat, reduksionisme yakni dunia dapat diketahui dengan memecah dunia tersebut kepada satuan-satuan kecil. Panas adalah gabungan dampak dari partikel gas dan cair. Bunyi adalah gerakan gelombang yang dibawa oleh medium yang bergetar. Baubauan muncul ketika molekul-molekul terbang memasuki hidung dan bereaksi dengan reseptor di dalamnya. Rasa adalah molekulmolekul yang mempengaruhi lidah. Dan warna tidak lebih dari radiasi elektromagnetik. Fenomena yang kompleks dapat disederhanakan menjadi unsur-unsur yang kecil. ${ }^{9}$

Kelima, determinisme, menyatakan bahwa dunia diatur

${ }^{6}$ Ibid., h. 4-6

${ }^{7}$ Tbid, h. 21. Dalam hal ini, Rolston meminjam teori Martin Buber bahwa hubungan pengamat dengan yang diamati bagaikan hubungan ' 1 dengan it', aku dengan objek yang tanpa perasaan dan nilai.

${ }^{8}$ Ibid.. h. 28. Bandingkan juga dengan Akhyar Yusuf Lubis, Paul Feyerabend, (Jakarta: Teraju. 2003), h. 58.

${ }^{9}$ Ibid., h. 38. 
hukum sebab akibat yang bersifat linier. Baik sebab maupun akibat terjadi pada tataran dunia empiris. Apapun yang terjadi sekarang terjadi karena sebab-sebab yang mendahuluinya, sebab-sebab yang bersifat empiris atau imanen. Dengan determinisme yang menggunakan proposisi 'jika-maka', ilmu pengetahuan dapat meramalkan dan juga mengendalikan pelbagai peristiwa di alam semesta. ${ }^{10}$

Sampai di sini, terlihat jelas seakan-akan metode yang digunakan dalam dunia sains berpijak pada patokan-patokan yang dapat terukur secara empirik, bersifat objektif, serta tanpa keterlibatan asumsi, praduga, atau prasangka si pengamat dan ilmuwan itu sendiri. Akan tetapi seperti ditegaskan Rolston, bahwa tidak ada penelitian ilmiah yang benar-benar objektif tanpa keterlibatan pengamat. Siapapun ilmuwannya, mereka pasti membawa kepercayaan, atau unsur subjektivitas mereka dalam menafsirkan fakta-fakta di jagad raya.

Meskipun teori dan fakta masing-masing dalam beberapa tingkat merupakan pengetahuan objektif dan mewakili dunia nyata, namun tidak dapat dielakkan keduanya adalah pengetahuan subjektif pula secara mutlak. Hal ini disebabkan, karena informasi yang diperoleh tersebut diproses oleh subjek-subjek yang bernama manusia. Orang-orang yang mengetahui tidak pernah sedikit lebih mengetahui daripada yang diketahui karena mengetahui adalah sebuah hubungan. ${ }^{11}$

Sebagai ilustrasi, seorang ilmuwan memilih apa yang dikaji dan bagaimana cara mengkajinya. Kapanpun dia membangun laboratorium, mempersiapkan beberapa eksperimen, memilahmilah fenomena-fenomena, atau menggunakan teori ke dalam observasi, maka dia sedang membuat jaring untuk mengail, dan apa yang ditangkapnya adalah flings; dari jaringnya sendiri. ${ }^{12}$

Pada titik ekstremnya, seseorang tidak dapat melihat apa yang tidak dicarinya, meskipun bukti yang ada lebih dari cukup. Seringkali apakah seseorang menjumpai dirinya sedang mencari tergantung pada apa yang tengah ia cari dan dengan

${ }^{10}$ Secara global bandingkan juga dengan Jalaluddin Rakhmat, Islam dan Pluralisme, (Jakarta: Serambi, 2006), h. 190-194.

${ }^{11}$ Rolston, Science..., h. 16.

${ }^{12}$ Ibid., h. 19. 
apa ia mencarinya. Di sini. Rolston menggarisbawahi: we interpret what we see in order to see it, setiap orang menafsirkan apa yang ia lihat agar ia dapat melihatnya. Ada sebuah prinsip subjektivitas atau presuposisi yang berperan dalam diri seorang ilmuwan dalam melihat (menafsirkan) fakta, sehingga implikasi lebih jauhnya: if I hadn't believed it, I wouldn't have seen it, jika seseorang sudah tidak mempercayai sesuatu, maka ia tidak akan dapat melihatnya. ${ }^{13}$

Bahkan lebih jauh, terkadang dan seringkali sebuah teori lahir dari sebuah trial and error yang tidak terduga sama sekali. Ketika sedang tidur, August Kekule memimpikan sebuah angan-angan tentang permainan atom-atom dan ular, ular yang menggigit ekornya sendiri. Sejak malam itu, ahli kimia yang terkenal tersebut mengembangkan struktur benzene. Fred Hoyle mencetuskan teori kekonstanan alam karena terinspirasi kejadian aneh saat ia menghilangkan sekrup dan paku. Dan Albert Einstein melaporkan bahwa ia mengawali teori relativitasnya, setidaknya sebagian dalam mimpi dan dengan menekankan kebebasan imajinasi, untuk kemudian baru diuji secara observasional. ${ }^{14}$

Dengan eksposisi diatas, bukan berarti menyangkalvaliditas teori-teori ilmiah atau metode-metode-penyelidikan ilmiah. Yang ingin disangkal dalam hal ini adalah klaim objektivitas, bebas nilai, dan tanpa keterlibatan unsur subjektivitas sang peneliti itu sendiri. Padahal lazimnya, fakta-fakta atau peristiwa alam disaring oleh konsep-konsep yang telah diciptakan terlebih dulu. Sehingga dalam tilikan kritis, fakta-fakta ilmiah tidak lebih merupakan bagian dari entitas subjektivitas sang pengamat. Fakta menjelma kebenaran kontekstual, bukan kebenaran faktual an sich. ${ }^{15}$

\section{Prinsip-Prinsip Dalam Penyelidikan Agama}

Memetakan pendekatan dalam lingkup agama merupakan persoalan yang complicated, dan acapkali herseberangan dengan pendekatan-pendekatan dalam dunia ilmiah. Namun setidaknya secara global, pendekatan agama berlandaskan pada beberapa prinsip berikut. Pertama, prinsip berpikir agamis meliputi empiris-

\footnotetext{
${ }^{13}$ Ibid., h. 8 \& 10.

${ }^{14}$ Ibid., h. 3-4.

${ }^{15}$ Ibid., h. 2-3.
} 
meta-empiris, rasional-intuitif, objektif-partisipatif, menggunakan secara eksplisit peran fungsi spiritual dan aksioma-aksiomanya yang dijabarkan dari ajaran agama.

Kedua, objek telaah agama mencakup juga alam metafisis dan mengakui peranan hati dan kalbu yang bersifat metafisikal dan dianggap dapat menyentuh kebenaran hakiki yang mempunyai tujuan akhir berupa keimanan dan ketakwaan kepada Sang Maha Pencipta Alam.

Ketiga, otoritas terakhir dalam agama ada pada Tuhan dan wahyu yang dibuktikan keabsahannya dengan pengalaman penganutnya.

Keempat, agama mengajukan pertanyaan-pertanyaan personal, sebuah pertanyaan eksistensial, why questions, yang berkenaan dengan makna, tujuan, dan asal-usul serta nasib akhir manusia, juga perasaan bersalah, kecemasan, dan kehilangan makna pada sisi lain. Kelima, agama acapkali menggunakan bahasa analogis dan simbolis karena berhubungan dengan eksistensi transenden seperti Tuhan, surga, neraka, pahala, kebaikan dan lainnya. ${ }^{16}$

Terlepas dari puspa ragam pendekatan dan prinsip tersebut, menurut Rolston semua perbincangan mengenai agama bermuara pada satu hal prinsipil yakni untuk menyibak makna. Jika sains menyingkap hubungan kausalitas yang bersifat objektif, maka agama ujung-ujungnya untuk menemukan makna yang bersifat subjektif, yang hanya dirasakan oleh orang yang bersangkutan. ${ }^{17}$

Bela Weissmahr menggambarkan makna sebagai apa yang memenuhi manusia, yang sesuai dengan kebutuhan-kebutuhan vital, rohani, personalnya, yang memenuhi kerinduannya akan pengakuan, keterlindungan, kebersatuan, yang karenanya ia merasa diri baik, yang membuat manusia sanggup untuk menerima lingkungannya, nasibnya, akhirnya dirinya sendiri seluruhnya. ${ }^{18}$

${ }^{16}$ Prinsip-prinsip tersebut diuraikan oleh Rolston secara sporadis, sehingga pemetaan ini pun cukup sulit untuk mengklasifikasi secara detil. Mengenai prinsipprinsip tersebut bisa dilihat Ibid., h. 20, 23, 28-30, dan 39-40. Bandingkan juga dengan Rakhmat, Psikologi...., h. 80-84.

${ }^{17}$ Rolston, Science........., h. 2.2-26.

${ }^{18} \mathrm{Di}$ sini kata "kita" saya ganti dengan manusia karena alasan akademik 
Sehingga ketika bersentuhan dengan alam semesta dalam segala aspeknya, manusia yang beragama akan selalu berusaha mencari dan menemukan makna dalam tataran eksperiensial bukan secara eksperimental, secara eksistensial bukan secara operasional. ${ }^{19}$

Dalam tilikan Rolston, ${ }^{20}$ untuk menyingkap makna, mensyaratkan paradigma Aristotelian yang menggunakan empat sebab: penyebah efisien (efficient cause/fa'il), penyebab final (final cause/ gāyah), penyebab material (material cause/madah), dan penyebab formal (formal cause/shürah). Dengan keempat penyebab di atas, Aristoteles ingin menjelaskan secara lengkap semua faktor. yang dapat menyebabkan suatu peristiwa ${ }^{21}$

Pertama, penyebab efisien. Inilah faktor yang menjalankan kejadian. Sumber dari permulaan atau awal dari sebuah perubahan, yang diidentifikasi oleh Aristoteles ${ }^{22}$ dan filsuf Arab Muslim alKindi dengan Tuhan atau dalam bahasa filsafatnya sebagai sebab pertama gerak alam semesta (the first mover of the universe). Sehingga Tuhan dipandang oleh keduanya sebagai sebab efisien alam semesta. Sampel demonstratif tentang hal ini mungkin konsep Ibn Sina mengenai Tuhan sebagai Wujud Niscaya (wajib al-wujud)

sebagai orang ketiga. Lihat Franz Magnis Suseno, Menalar Tuhan, (Yogyakarta: Kanisius, 2006), h. 172.

${ }^{19}$ Rolston, Science...., Op.Cit.,. h. 7.

${ }^{20}$ Ibid., h. 34-35.

${ }^{21}$ Untuk lebih detilnya mengenai eksplorasi keempat sebab tersebut dengan paradigma Aristotelian, lihat Abed al-Jabiri, Bunyah al-AqI al-Arabi, (Beirut: AlMarkaz al-tsaqafi al-arabi, 1993), h. 398; Abed al-Jabiri. Tragedi inteleklual, tcrj. Aland Abdillah, (Yogyakarta: Pustaka Alief, 2003), h. 247; Bandingkan dengan K. Ik-Hens, Sejarah Filsafat Yunani, (Yogyakarta: Kanisius, 1999), h. 173-174.

${ }^{22}$ Namun Tuhan Arislotelcs masili diperdebatkan. Menurut Jabiri, Tuhan Aristoteles sebagai penggerak pertama (al-iritihanik al-awwal), nampak sekadar asumsi ilmiah untuk menafsirkan prinsip gerak sehingga tidak lebih dari tuntutan logika semata. Abed al-Jabiri, Talavin al-AqI al-Arabi, (Beirut: Markaz Dirāsah al-Wahdah al-Arabiyah, 1983), h. 27-28; Resell menyatakan bahwa Aristoteles mendiskusikan mengenai Tuhan yang transenden, hanya saja dengan uraian filosofis yang mampu dicerna nalar dan sepenuhnya rasional. Bertrand Russell, History of Western Philosophy, (London: Unwin Univcrsitv Books, 1955), h. 180-184; Senada dengan Russell, Amstrong melihat Aristoleles jelas menggagas konscp Tuhan, tapi Tuhan yang tidak mewahyukan dirinya dalam scjarah, tidak mcnciptakan alam, \& tidak mengadili di Hari Kiamat. Karen Armstrong, A History of God, (New York: Ballanline Books, 1993), h. 171. 
yang menjadi sebab wujudnya alam semesta. ${ }^{23}$

Wujud Niscaya adalah wujud yang senantiasa harus ada, dan tidak boleh tidak ada. Alam semesta adalah wujud mungkin, wujud yang boleh saja ada atau tidak. Akan tetapi, nyatanya alam ada, maka ia dipastikan sebagai wujud yang mungkin. Terma "mungkin" menurut Ibn Sina adalah potensial, kebalikan dari aktual. Dengan mengatakan bahwa alam ini mungkin pada dirinya, berarti sifat dasar alam adalah potensial, boleh ada, dan tidak bisa mengada dengan sendirinya. Karena alam itu potensial, ia tidak mungkin ada tanpa adanya sesuatu yang telah aktual, yang telah mengubahnya dari potensial menjadi aktual. Sesuatu yang aktual yang telah mengubah alam potensial menjadi aktualitas, itulah Tuhan sebagai Wujud Niscaya. ${ }^{24}$ Di sini, Tuhan merupakan Wujud Niscaya (Necessary Being) sebagai Penyebab pertama (first cause) dan sumber utama eksistensi. ${ }^{25}$

Kedua, sebab final, yakni tujuan yang untuk mencapainya sesuatu dilakukan atau tujuan untuk apa sesuatu itu diadakan. Dalam epistemologi Islam, sebab final menjelaskan bahwa alam semesta mempunyai tujuan tertentu bukan kebetulan atau sama sekali tanpa tujuan. Alam diciptakan sebagai tanda Tuhan, yang menunjukkan bukan hanya keberadan-Nya, melainkan juga kebesaran, Kebijaksanaan, kasih sayang, dan sebagainya demi kebahagiaan umat manusia. ${ }^{26}$ Jadi dalam bingkai filsafat, alam semesta bersifat teleologis yakni mempunyai tujuan yang sengaja didesain oleh Desainer Agung, there is Desaigner behind the design. ${ }^{27}$

Ketiga, sebab materiil yakni bahan untuk membuat sesuatu. Sebab materiil dengan demikian, berbicara tentang materi yang menyusun sebuah objek, dan karena itu merupakan constitutive

\footnotetext{
${ }^{23}$ Mulyadhi Kartanegara, Integrasi Пmu, (Bandung: Arasy, 2005), h. 154.

${ }^{24}$ Ibid., h. 34-36.

${ }^{25}$ Oliver Leaman, A Brief Introduction to Islamic Philosophy, (Cambridge: Polity
} Press, 1999), h. 90.

${ }^{26}$ Mulyadhi, Integrasi....., h. 156.

${ }^{27}$ Perbincangan konscp teleologis agak luas dan kritis dibahas dalam Joseph Runzo, Global Philosophy of Religion, (Oxford: Oneworld Publications, 2001), h. 85-92. Bandingkan dengan Julian Baggini, Lima Tema Utama Filsafal. terj. Nur Zaen Hai, (Jakarta: Teraju, 2004), h. 165-168. 
nelericil-nya, di mana sebuah perubahan berlangsung. Dalam sampel patung, maka sebab materiilnya adalah perunggu yang setelah dipahat kemudian mengambil bentuk patung. Dalam bahasa filsafat, materi sama dengan potensi. Jadi ketika bicara perunggu, maka sebelum mendapat bentuk, perunggu merupakan potensi yang bisa menerima berbagai bentuk: bisa patung, piala, medali, benda-benda rumah tangga, dan sebagainya.

Berbagai bentuk dari pelbagai perunggu yang telah diolah itulah yang disebut sebagai sebab terakhir, sebab formal. Melalui sebab formal, sebuah objek memperoleh sifat-sifat yang khas yang membedakannya dengan yang lain. Arti penting sebab formal ini dapat dilihat dari perspektif para filosof bahwa tanpa bentuk, maka materi alam akan tetap menjadi potensi, dan hanya dengan bergabungnya bentuk dengan materi, maka sesuatu itu akan mewujud atau mengaktual, seperti yang bisa disaksikan sekarang.

Dengan demikian, menjadi jelas betapa keempat sebab ini merupakan satu kesatuan tunggal dari penjelasan ilmiah yang tidak akan sempurna kalau seseorang meninggalkan, atau hanya mengambil salah satunya. Hanya dengan menjelaskan keempat sebab bagi sebuah objek yang sedang ditelaah, maka seorang pengamat akan memperoleh pengetahuan yang holistik dan komprehensif sehingga membuahkan makna dalam kehidupan. ${ }^{28}$

\section{Catatan Kritis}

Melalui eksposisi di atas, terlihat bagaimana sains mempunyai metodenya sendiri yang bersifat ilmiah sebagaimana agama juga memiliki metodenya tersendiri untuk menyibak makna. Akan telapi paradigma Aristotelian yang dipertahankan dan dikembangkan oleh pelbagai filsuf termasuk filsuf Muslim, menurut Rolston justru mengalami transformasi fundamental. Rolston menyebut transformasi fundamental dalam penjelasan ilmiah ini sebagai “Revolusi dalam Penjelasan" ketika empat segi penjelasan ilmiah Aristotelian oleh para ilmuwan dan filosof Barat, termasuk Newton, Hume, dan Jacques Loeb dibatasi hanya kepada dua sebab saja: sebab materiil dan sebab efisien, sedangkan sebab formal dan final ditolak karena menurut mereka lebih cenderung

${ }^{28}$ Mulyadhi, Integrasi ........h. 159-161. 
pada makna ${ }^{29}$

Padahal kajian ilmiah harus hanya berkaitan dengan fakta. Sehingga sejak itu, kajian ilmiah hanya berkutat dengan fakta dan meninggalkan dimensi makna yang menurut mereka, lebih berkaitan dengan kepercayaan atau agama. ${ }^{30}$ Dan dalam perkembangan selanjutnya pada masa sekarang, satu-satunya sebab yang masih diperhatikan dalam uraian ilmiah sains modern adalah sebab efisien, yang dipandang sebagai sebab terjadinya gerak atau perubahan di alam semesta. Meskipun begitu, para ilmuwan modern menganggap sebab efisien dunia materiil berasal dari dirinya sendiri bukan dari luar, mereka menyebutnya sebagai imanen. ${ }^{31}$

Dengan demikian, lagi-lagi teleologis kosmis yang bercorak transenden dan penciptaan semesta yang bermuara kepada Tuhan kehilangan jejaknya. Selain itu, bahkan ketika para ilmuwan modern mempertahankan sebab efisien sebagai prinsip penjelasan ilmiah yang tidak bisa dilenyapkan, tetapi dengan pemahamannya yang diperbaharui sebagai sebab imanen. pertanyaan siapa menciptakan alam, tetap tidak akan terjawab dengan baik secara ilmiah. Alasannya adalah karena menurut ajaran sebab imanen (immanent cause), sebab gerak alam tidak perlu dicari di luar dirinya, tetapi cukup di dalam dirinya sendiri (imanen).

Dengan demikian, dapat dipahami ketika beberapa ilmuwan modern menganggap alam ini sebagai otonom, dan karena itu tidak memerlukan pencipta atau sebab di luar dirinya. Alam pun kemudian dikonsepsikan sebagai sesuatu yang dapat menciptakan dirinya sendiri (self originating/creating) tanpa campur tangan sebuah agen eksternal. Dengan demikian pada gilirannya, tidak ada makna dalam penciptaan semesta dan tidak ada tempat bagi peran Tuhan di bumi. ${ }^{32}$

\footnotetext{
h. 126.

${ }^{30}$ Mulyadhi Kartanegara, Menembus Batas Waktu, (Bandung: Mizan, 2002), h. 86 .

${ }^{31}$ Kartanegara, Integrasi..., h. 149.

${ }^{32}$ Ibid., h. 151-152.
}

${ }^{29}$ Mulyadhi kartanegara, Menyibak Tirai Kejahilan, (Bandung: Mizan, 2003), 
Dalam konteks inilah, Huston Smith ${ }^{33}$ mengkritisi paradigma sains yang tidak mau membuka diri terhadap fenomena dibalik fakta-fakta. Karena di awal milenia ketiga ini sains sangat tertutup, Smith memandang sains sudah menjadi saintisme. Dengan menggunakan metafora terowongan. Smith menegaskan bahwa saintisme dan materialisme telah bersekongkol dalam menghalangi orang melihat gambaran yang lebih besar. Saintisme adalah keyakinan bahwa metode ilmiah adalah satu-satunya, atau sekurang-kurangnya, cara memperoleh kebenaran yang paling dapat dipercaya dan bahwa entitas material merupakan unsur eksistensi yang paling mendasar. ${ }^{34}$

Dalam metafora terowongannya Smith, saintisme merupakan fondasi atau lantai. Pendidikan tinggi, hukum. dan media masing-masing menggambarkan sisi dan bagian atas terowongan itu. Hasilnya adalah: sebuah orientasi sempit berorientasi ke dalam yang secara efektif menghalangi pandangan metafisika. Jadi bagi Smith, pendidikan tinggi, hukum, dan mediamedia populer di Barat telah mempropagandakan saintisme. Smith jelas tidak menentang sains atau ilmu pengetahuan. Sebaliknya ia sangat menghargai penelitian dan prestasi ilmiah. la hanya menyanggah saintisme bukan sains itu sendiri..$^{35}$ Dalam perspektif Charles Kimball, Smith hanya mengajak manusia keluar dari terowongan dehumanisasi, suatu ruang tanpa transendensi. Agama mempunyai arti karena ia membukakan manusia ke suatu jagad yang dipenuhi dengan cita-cita mulia, agung, luhur, kedamaian, dan keindahan. ${ }^{36}$

Dalam konteks ini. Smith, seperti halnya Rolston atau

${ }^{33}$ Lebih detilnya lihat Huston Smith, Why Religion Matters, (Harper San Fransisco: Harper Collins Publishers, 2001).

${ }^{34}$ Tentang saintisme lihat Louis Leahy, Aliran-Aliran BesarAteisme, (Yogyakarta: Kanisius, 1985). h. 138-140.

${ }^{35}$ Dalam karya scbelumnya yang juga sangat terkenal. Forgotten truthal. Smith membagi tiga level realitas: pertama, terrestrial yakni tataran material. Kedua, intermediate, yakni wilayah psikis. Ketiga. celestial, yaitu wilayah ketuhanan. Jadi eksistensi realitas bukan hanya terdiri dari materi tapi juga meliputi eksistensi transenden atau ketuhanan. Huston Smith, Forgotten Truth, (Harper San Fransisco: Harper Collins Publishers. 1992), h. 34-59.

${ }^{36}$ Charles Kiniball, Kala Againa Jadi Bencana, terj. Nurhadi, (Bandung: Mizan, 2003), h. 69-75. 
juga Barbour, tampaknya menginginkan adanya interaksi, dialog, bahkan integrasi antara sains dan agama. Bukan hanya sains yang harus membuka diri terhadap agama, tetapi dalam tilikan Rolston, keyakinan-keyakinan agama juga harus diuji di bawah terang perspektif-perspektif sains untuk membersihkan agama dari pandangan-pandangan primitif, takhayul, serta keyakinan buta tanpa argumentasi rasional. ${ }^{37}$

\section{E. Penutup}

Akhirnya, sebagai pamungkas wacana ini, kiranya penulis tidak mampu melukiskan keterkaitan sains dan agama dalam frase yang singkat namun padat seindah yang dilukiskan oleh Murtadha Muthahhari empat dasawarsa silam: "Sains memberi kita kekuatan dan pencerahan, dan keimanan memberi cinta, harapan, dan kehangatan. Sains menciptakan teknologi, dan keimanan menciptakan tujuan. Sains memberi kita momentum dan keimanan memberi kita arah. Sains berarti kemampuan, dan keimanan adalah kehendak baik. Sains menunjukkan kepada kita apa yang ada di sana, sementara keimanan mengilhami kita tentang apa yang mesti kita kerjakan. Sains adalah revolusi eksternal, dan keimanan adalah revolusi internal. [ ]

\section{Daftar Pustaka}

Armstrong, Karen, A History of God, New York: Ballanline Bokks. 1993.

Baggini, Julian, Lima Tema Utama Filsafal. terj. Nur Zaen Hai, Jakarta: Teraju, 2004.

Barbour, Ian G., Juru Bicara Tuhan, terj. E.R. Muhammad, Bandung: Mizan, 2002.

, Menemukan Tuhan dalam Sains Kontemporer dan Agama, terj. Fransiskus Borgias, Bandung: Mizan, 2005.

Haught, John F. , Perjumpaan Sains dan Agama, terj. Fransiskus

${ }^{37}$ Rolston, Science........, h. 7. 
Borgias, Bandung: Mizan, 2004. Ik-Hens, K., Sejarah Filsafat Yunani, Yogyakarta: Kanisius, 1999. al-Jabiri, Abed, Bunyah al-AqI al-Arabi, Beirut: al-Markaz al-Ṣaqafi al-Arabi, 1993.

, Talavin al-AqI al-Arabi, Beirut: Markaż Dirāsat al-Wahdah al-Arabiyah, 1983.

, Tragedi inteleklual, tcrj. Aland Abdillah, Yogyakarta: Pustaka Alief, 2003.

Hidayat, Komaruddin, Tragedi Raja Midas, Jakarta: Paramadina, 1998.

Kartanegara, Mulyadhi, Integrasi Ilmu, Bandung: Arasy, 2005. , Menembus Batas Waktu, Bandung: Mizan, 2002. , Menyibak Tirai Kejahilan, Bandung: Mizan, 2003.

Kiniball, Charles, Kala Agama Jadi Bencana, terj. Nurhadi, Bandung: Mizan, 2003.

Leahy, Louis, Aliran-Aliran Besar Ateisme, Yogyakarta: Kanisius, 1985.

Leaman, Oliver, A Brief Introduction to Islamic Philosophy, Cambridge: Polity Press, 1999. Madjid, Nurcholish, Islam Doklrin dan Peradaban, Jakarta: Paramadina, 1995.

Lubis, Akhyar Yusuf, Paul Feyerabend, Jakarta: Teraju. 2003

Rakhmat, Jalaluddin, Islam dan Pluralisme, Jakarta: Serambi, 2006. , Psikologi Agama, Bandung: Mizan, 2003.

Rolston III, Holmes, Science and Religion A Critical Survey, New York: Random House, 1987.

Runzo, Joseph, Global Philosophy of Religion, Oxford: Oneworld Publications, 2001.

Russell, Bertrand, History of Western Philosophy, London: Unwin Univcrsitv Books. 1955.

Smith, Huston, Forgotten Truth, Harper San Fransisco: Harper Collins Publishers. 1992. , Why Religion Matters, Harper San Fransisco: Harper Collins Publishers, 2001.

Suseno, Franz Magnis, Menalar Tuhan, Yogyakarta: Kanisius, 2006. 